\title{
PROTECCIÓN DE LOS MENORES EXTRANJEROS NO ACOMPAÑADOS EN LA UNIÓN EUROPEA
}

\section{Protection of unaccompanied minor migrants in the European Union}

\author{
Enrigueta Serrano Caballero*
}

\section{RESUMEN}

El objetivo de este artículo es identificar y dar a conocer las normas del derecho internacional y del derecho de la Unión Europea (UE) acerca de la protección de los menores extranjeros no acompañados solicitantes de asilo (véase la Directiva 2011/95/UE del Parlamento Europeo y del Consejo de 13 de diciembre de 2011), a fin de dar un poco de luz sobre el tema de la protección de los menores extranjeros no acompañados que llegan al territorio de la UE. La cuantía y la naturaleza de la emigración de los menores de edad no acompañados que solicitan protección varían de un Estado a otro. El valor de esta investigación es abordar el estudio de la manera en que durante los últimos años se ha incrementado el número de menores no acompañados que emigran a alguno de los Estados miembros de la UE, indocumentados y sin tener en cuenta las normas de extranjería de los Estados que la conforman. El trabajo concluye que, a pesar de las deficiencias de la normativa comunitaria en lo que respecta al control y la falta de competencia comunitaria para proteger al menor extranjero no acompañado, la UE debe hacer prevalecer en todo su territorio el interés superior del menor.

Palabras Clave: menores no acompañados, Refugiados, protección internacional, Unión EUROPEA, DERECHOS DEL NIÑO.

* El Colegio de San Luis, Programa de Estudios Políticos e Internacionales. Correo electrónico: eserrano@ colsan.edu.mx. 


\section{Abstract}

The objective of this article is to identify and know the rules of international law and the law of the European Union (EU) on the protection of unaccompanied foreign applicants for asylum (see Directive 2011/95/EU of the European Parliament and of the Council of 13 December 2011), to give a bit of light to the subject of the protection of unaccompanied foreign minors that arrive in the territory of the EU. The number and nature of the foreign minors seeking protection vary from one State to another. The value of this research is to approach the study of how in recent years there has been an increase in the number of unaccompanied minors who migrate to one of the Member States of the EU, undocumented and without taking into account the rules of aliens of the States that make it up. The paper concludes that despite the shortcomings of Community legislation in relation to the monitoring and the lack of community competence to protect the unaccompanied child, the EU must prevail in all its territory the best interests of the child.

KEYWORdS: UNACCOMPANIED MINORS, REFUgEES, INTERNATIONAL PROTECTION, EUROPEAN UNION, RIGHTS OF THE CHILD.

Recepción: 15 de abril de 2016.

Dictamen 1: 14 de noviembre de 2016.

Dictamen 2: 22 de febrero de 2017. 
No me pregunte por qué soy un refugiado, no lo sé.

Pregunte a los mayores el porqué.

LiBAN AHMED HaBib, 10 AÑOS DE EDAD.

Refugiado etíope en Kenia (Sybella Wilkes, 1999).

\section{INTRODUCCIÓN}

La migración de menores de edad ha existido en las grandes migraciones producidas a lo largo de la historia, bien acompañados de sus familias o de manera autónoma; pero no fue hasta la década de los 90 del siglo XX cuando suscito el interés de los Estados y de las instituciones.

La migración de menores ha sido entendida como parte de una estrategia familiar y su protagonismo ha sido subsumido a esta. Varias investigaciones han comenzado a prestar más atención a los menores en los procesos migratorios. Dado que la migración de menores no acompañados ${ }^{1}$ es un nuevo actor de la inmigración en general, este sector se convierte en una prioridad política y social para los Estados miembros de la UE, quienes tienen el reto de construir una política común para hacer frente a este fenómeno.

Los motivos de los menores extranjeros no acompañados (MENA, en adelante) para emigrar son muchos y se encuentran interrelacionados. Algunos de los menores extranjeros no acompañados que llegan a territorio europeo escapan de guerras, conflictos, terrorismo, situaciones de persecución y discriminación, catástrofes naturales, hambre, pobreza, sequías, o simplemente son enviados por sus familias con la expectativa de encontrar un trabajo o acceder a unas condiciones mejores de vida y de educación que carecen en sus países de origen, y muchos de ellos son potencialmente solicitantes de asilo. Sea cual sea el motivo, su minoría de edad y el hecho de que no estén acompañados por sus progenitores o tutores les convierte en un grupo vulnerable - por la condición que impone su grado de desarrollo y su situación de indefensión- que debe ser objeto de atención y protección por parte de los poderes públicos, una protección que tiene su marco de referencia específico en la Convención de los Derechos del Niño de las Naciones Unidas de 1989, y

${ }^{1}$ La expresión "menores no acompañados" se refiere a los individuos de edad inferior a 18 años que entran en territorio europeo sin que en el Estado de acogida haya un adulto responsable de ellos. En la Unión Europea se establecen normas relativas a los requisitos para el reconocimiento de nacionales de terceros países o apátridas como beneficiarios de protección internacional. 
también en lo relativo a los solicitantes de asilo en la Convención de Ginebra de 1951 y el Protocolo de 1966 sobre el Estatuto de Refugiados.

En 2015 se produjo un aumento de inmigración irregular en la UE, resultado de diversos factores: la oleada de conflictos en Oriente Próximo (en especial, los problemas en Libia y Siria); la presión demográfica en África; el aumento de tráfico ilegal de personas como consecuencia del desarrollo de mafias organizadas; la emigración económica procedente de los Balcanes, y las propias dificultades de la UE para gestionar de manera homogénea sus fronteras.

Los menores migrantes extranjeros no acompañados no configuran un colectivo homogéneo. Estos son construidos y categorizados como "menores extranjeros no acompañados”, y son sujetos de protección bajo una lógica de control que problematiza e invisibiliza su protagonismo y autonomía, al tiempo que oculta los factores y lógicas que motivan sus trayectorias migratorias. Los MENA plantean una problemática definida por su doble situación de inmigrantes ilegales y de menores de edad, que les garantiza una protección que no siempre coincide con la ayuda que ellos necesitan o desean recibir (Durán, 2011, p. 12; Horcas, 2016, pp. 11, 15).

Debemos señalar que los primeros casos de menores extranjeros no acompañados se dieron en medio de una laguna jurídica, por lo que cada Estado de la UE tuvo que hacer frente a este fenómeno creando una respuesta legal dentro de su propio territorio (Senovilla, 2014). A partir de la constante llegada de menores extranjeros no acompañados en la década de los 90 del siglo XX, las instituciones europeas incorporaron la figura de "menor no acompañado" en sus directivas y reglamentos y en la construcción de una política en materia de inmigración y de asilo comunes (Horcas, 2016, pp. 14-15).

El objetivo de este artículo es identificar y conocer el marco normativo internacional y comunitario respecto de la protección de los MENA solicitantes de asilo en la UE, para dar un poco de luz sobre el problema de la protección internacional de estos en la actual crisis migratoria y humanitaria que acontece en la UE. Este trabajo es una aproximación al tema; no pretende hacer un análisis exhaustivo de la protección internacional de los MENA en la UE, tema en el que hay que seguir trabajando.

El trabajo se ha dividido en tres apartados bien diferenciados. En el primero se describe la situación de los menores extranjeros no acompañados que llegan a la UE; en el segundo se abordan algunas cuestiones conceptuales sobre los MENA que solicitan asilo en la UE, y acto seguido se aborda el marco jurídico internacional y comunitario, a pesar de que, a la fecha en que se escribió este artículo (2016), no 
existen normas específicas y obligatorias para todos los Estados miembros de la UE que permitan abordar la protección de los MENA de forma global.

Para ello, se revisaron textos jurídicos y fuentes legislativas internacionales sobre la infancia, derechos humanos, así como las normas europeas sobre migración, asilo y refugio, y bases de datos estadísticos sobre los MENA en diversas fuentes comunitarias (Frontex, Eurostat), así como informes e investigaciones auspiciados por organizaciones internacionales, tales como el Alto Comisionado de las Naciones Unidas para los Refugiados (ACNUR), el Fondo de las Naciones Unidas para la Infancia (UNICEF), la Oficina de Naciones Unidas contra la Droga y el Delito (UNODOC), la Organización Internacional para las Migraciones de Naciones Unidas (OIM), y organizaciones de la sociedad civil especializada (Amnistía Internacional, Save The Children, Human Rights Watch, entre otros). Todo ello nos ayudó a conocer más de cerca la complejidad que entraña la protección de los menores extranjeros no acompañados que llegan a territorio comunitario. En este sentido, hay que señalar el prolífero desarrollo de investigaciones y la variedad de análisis jurídicos referentes a los MENA que se abocan a la temática de la protección, defensa, derechos de los menores extranjeros no acompañados que llegan a territorio europeo. Este es uno de los ámbitos acerca del cual más se ha publicado durante los últimos años, pero en este trabajo no vamos a mencionarlos todos, sino aquellos que en nuestra opinión son los más relevantes: Claro y Lázaro (2013); Durán (2011) Lázaro y Moroy (2010), Moraga (2015), Ortega (2006) y Senovilla (2007, 2009, 2013, 2014).

\section{Situación DE LOS MENORES EXTRANJEROS NO ACOMPAÑADOS EN LA UNIÓN EUROPEA}

En los últimos años, según datos oficiales de la Unión Europea, ${ }^{2}$ la llegada de los menores extranjeros no acompañados no es un fenómeno eventual, sino una particularidad en realidad preocupante de la inmigración hacia el territorio de la UE. Abordar este asunto no es nada fácil, ya que se carecen de datos concretos y fiables, porque muchos de los MENA, al introducirse en el territorio de la UE, no son observados, ni registrados; aun así, basta con consultar los datos proporcionados por Eurostat y Frontex relativos a los MENA que al llegar al territorio europeo solicitan protección internacional. En 2015, llegó a Europa la mayor

2 Datos proporcionados por Eurostat y Frontex (2008-2015). 
oleada de extranjeros - más de un millón de personas 3 — en busca de protección internacional (véase la gráfica 1), lo cual ha dificultado las concesiones de asilo. Frente al elevado número de personas solicitantes de asilo y protección que llega a los países de UE, se han implementado políticas de control de los flujos migratorios que dificultan la llegada de estos al territorio europeo.

\section{Gráfica 1. Solicitantes de ASIlo en La unión Europea (2008-2015)}

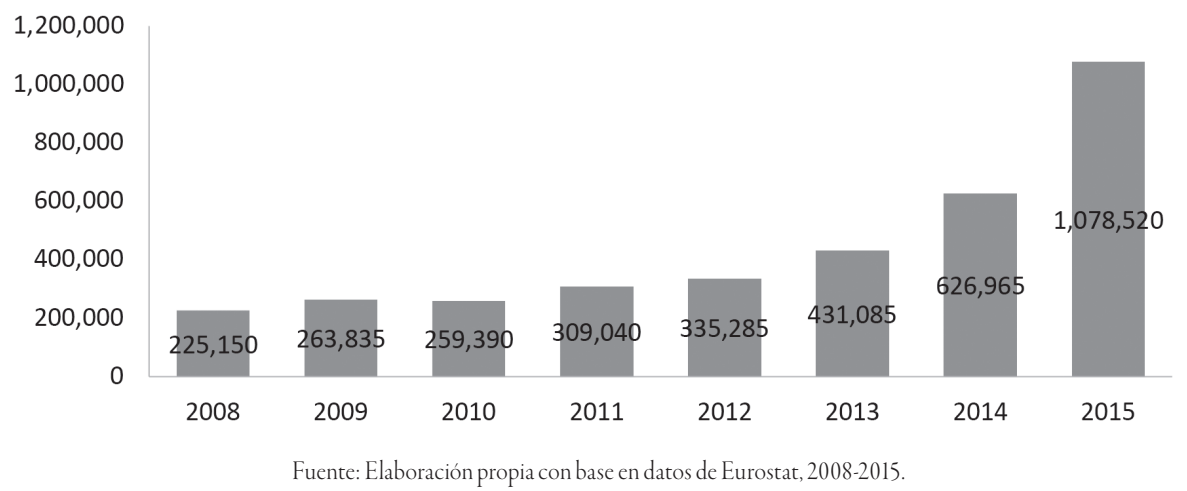

Desde 2008, más de 750000 personas que solicitaron asilo vieron sus demandas aceptadas (Abellán, 2015). En 2014 hubo un incremento de 50 por ciento en el número de personas que obtuvieron el estatus de refugiado o algún tipo de garantía internacional con respecto de 2013 (Eurostart, 2015).

Entre los refugiados que llegan a Europa hay miles de menores que viajan solos, sin padres, y que solicitan asilo. Se estima que el número de MENA que solicitan asilo a la UE se ha ido incrementando desde 2010, alcanzando 25300 menores que solicitaron protección internacional en 2013 en 77 países, más de la mitad en Europa: 12730 (CEAR, 2015) (véase la gráfica 2). Sin embargo, no es fácil obtener datos de los MENA que no solicitan asilo, y se estima que esta cifra fue superior a 8500 menores en 2013 (European Migration Network, 2015).

En la gráfica 2 y en la tabla 1 nos damos una idea bastante fiable — a partir de los datos proporcionados por Eurostat— de la magnitud del fenómeno de los MENA

\footnotetext{
3 Según datos de la Organización Internacional para las Migraciones, el balance actualizado hasta el 15 de febrero de 2016 confirma una cifra de 10011712 . Gran parte de estos refugiados han llegado a territorio europeo a través de Grecia, país por el que entraron 853650 refugiados en 2015, en su mayoría sirios y afganos. En total, cerca de 3770 personas han perdido la vida en su intento por buscar un futuro mejor en Europa.
} 
por el número de solicitudes de asilo que se han realizado. Cabe señalar que hay menos estadísticas sobre los MENA irregulares o que han sido objeto de la trata de seres humanos o del crimen organizado. El número de MENA que solicitan asilo en la UE se ha incrementado a partir de 2010, aunque esta tendencia no es homogénea y depende del Estado específico de que se trate. Entre 2013 y 2014, la cifra se duplicó de 12730 a 23150 (véase la tabla 1), y de enero a septiembre de 2015 alcanzó un total de 106 000, según datos de Eurostat. En 2015, 22255 menores no acompañados solicitaron asilo en Alemania y 35250 en Suecia; 57 por ciento (50 500 personas) de ellos tenían entre 16 y 17 años, mientras que los menores de 14 a 15 años representaban 29 por ciento (25 800 personas).

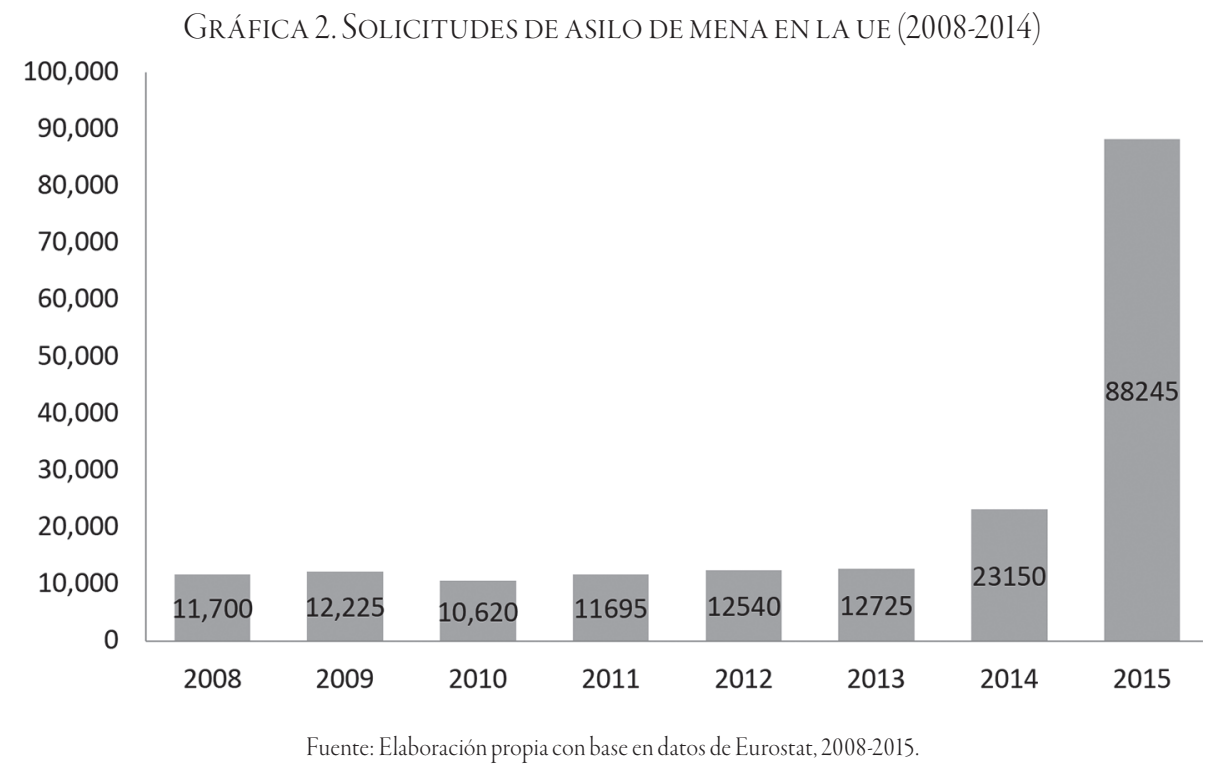

La cifra supone una cuarta parte de todos los solicitantes de asilo. Como se puede observar, el alcance y la procedencia de estos flujos migratorios varía de un Estado miembro (EM) a otro. Aunque 80 por ciento de quienes llegan a la UE pueden convertirse en candidatos a la protección alegando motivos de persecución, la proporción de concesión ha permanecido bastante estable (Abellán, 2015). Además, los porcentajes por país demuestran grandes disparidades y la falta de homogeneidad en las políticas en la UE, variando desde 94 por ciento de reconocimiento que concede Bulgaria o 77 por ciento de Suecia hasta nueve por ciento de Hungría 
o 11 por ciento de Croacia (Eurostart, 2015). Durante el primer cuarto de 2016, la UE registró 287100 solicitudes, de la cuales 60 por ciento fueron aceptadas. Alemania, Italia, Francia, Suecia, Países Bajos y Reino Unido fueron los que más solicitudes procesaron (Eurostat, 2016).

TABLA 1. SOLICITANTES DE ASILO CONSIDERADOS COMO

MENORES NO ACOMPAÑADOS. DATOS ANUALES, 2008-2015

\begin{tabular}{|c|c|c|c|c|c|c|c|c|}
\hline & 2008 & 2009 & 2010 & 2011 & 2012 & 2013 & 2014 & 2015 \\
\hline UE (28 países) & $11695^{(\mathrm{d})}$ & $12190^{(d)}$ & $10610^{(\mathrm{d})}$ & $11690^{(\mathrm{d})}$ & 12540 & 12725 & 23150 & 88245 \\
\hline Bélgica & 470 & 705 & 860 & 1385 & 975 & 415 & 470 & 2650 \\
\hline Bulgaria & 15 & 10 & 20 & 25 & 60 & 185 & 940 & 1815 \\
\hline República Checa & 35 & 10 & 5 & 10 & 5 & 0 & 5 & 15 \\
\hline Dinamarca & 300 & 520 & 410 & 270 & 355 & 350 & 815 & 2125 \\
\hline Alemania & 765 & 1305 & 1950 & 2125 & 2095 & 2485 & 4400 & 14440 \\
\hline Estonia & 0 & 0 & 0 & 0 & 0 & 5 & 0 & 0 \\
\hline Irlanda & 100 & 55 & 35 & 25 & 25 & 20 & 30 & 35 \\
\hline Grecia & 295 & 40 & 145 & 60 & 75 & 325 & 440 & 420 \\
\hline España & 10 & 20 & 15 & 10 & 15 & 10 & 15 & 25 \\
\hline Francia & 410 & 445 & 610 & 595 & 490 & 365 & 270 & 320 \\
\hline Croacia & $:$ & $:$ & $:$ & $:$ & 70 & 55 & 10 & 5 \\
\hline Italia & 575 & 415 & 305 & 825 & 970 & 805 & 2505 & 4070 \\
\hline Chipre & 70 & 20 & 35 & 15 & 25 & 55 & 50 & 105 \\
\hline Letonia & 5 & 0 & 5 & 0 & 0 & 5 & 0 & 10 \\
\hline Lituania & 0 & 5 & 10 & 10 & 5 & 0 & 5 & 5 \\
\hline Luxemburgo & 0 & 10 & 20 & 20 & 15 & 45 & 30 & 105 \\
\hline Hungría & 175 & 270 & 150 & 60 & 185 & 380 & 605 & 8805 \\
\hline Malta & 20 & 45 & 5 & 25 & 105 & 335 & 55 & 35 \\
\hline Países Bajos & 725 & 1040 & 700 & 485 & $380(\mathrm{p})$ & $310(\mathrm{p})$ & 960 & 3855 \\
\hline Austria & 695 & 1040 & 600 & 1005 & 1375 & 935 & 1975 & 8275 \\
\hline Polonia & 375 & 360 & 230 & 405 & 245 & 255 & 185 & 150 \\
\hline Portugal & 5 & 0 & 5 & 5 & 10 & 55 & 15 & 50 \\
\hline Rumania & 55 & 40 & 35 & 55 & 135 & 15 & 95 & 55 \\
\hline Eslovenia & 20 & 25 & 25 & 60 & 50 & 30 & 65 & 40 \\
\hline Eslovaquia & 70 & 30 & 5 & 20 & 5 & 5 & 10 & 5 \\
\hline Finlandia & 705 & 535 & 315 & 150 & 165 & 160 & 195 & 2535 \\
\hline
\end{tabular}


TABLA 1. SOLICITANTES DE ASILO CONSIDERADOS COMO

MENORES NO ACOMPAÑADOS. DATOS ANUALES, 2008-2015

\begin{tabular}{lrrrrrrrr}
\hline & 2008 & 2009 & 2010 & 2011 & 2012 & 2013 & 2014 & 2015 \\
\hline Suecia & 1510 & 2250 & 2395 & 2655 & 3575 & 3850 & 7045 & 35250 \\
\hline Reino Unido & 4285 & 2990 & 1715 & 1395 & 1125 & 1265 & 1945 & 3045 \\
\hline Islandia & 0 & 0 & 0 & 0 & 5 & 0 & 0 & 5 \\
\hline Liechtenstein & 0 & 15 & 0 & 0 & 0 & 0 & 0 & 5 \\
\hline Noruega & 1045 & 1820 & 630 & 635 & 705 & 670 & 940 & 5050 \\
\hline Suiza & 595 & 415 & 220 & 310 & 495 & 355 & 775 & 2670 \\
\hline
\end{tabular}

Fuente: Eurostat (14 de julio de 2016).

Los patrones de actuación dela UE respectodel reconocimientodelos derechos delos menores extranjeros no acompañados son adoptados en virtud de la Carta de los Derechos Fundamentales de la UE (en adelante, CDFUE) y de la Convención sobre los Derechos del Niño de las Naciones Unidas (véase Asamblea General de las Naciones Unidas, Convención sobre los Derechos del Niño de 20 de noviembre de 1989).

\section{QUÉ SE ENTIENDE POR “MENOR EXTRANJERO NO ACOMPAÑADO”}

El concepto de menor de edad extranjero no acompañado que emigra de forma autónoma sin ningún miembro de su familia o adulto que lo acompañe se cruza con las formas de gobierno sobre la migración (Jiménez, 2011; Monteros, 2007). El "menor extranjero no acompañado" es resultado de una construcción social y jurídica, como ya se había mencionado anteriormente. Desde los marcos normativos, se les denomina "menores no acompañados", categoría que oculta la complejidad social del menor, sus trayectorias personales, laborales, sociales y educativas. Para Vacchiano y Jiménez (2011), conforman una categoría "única”, al ser menores sujetos de derecho, menores de edad, extranjeros y objetos de control, a los que hay que vigilar y repatriar. Los MENA son los niños, jóvenes y adolescentes que migran solos e irregularmente a Europa. Jóvenes que viven una doble condición: de menores (a quienes hay que proteger) y extranjeros (a quienes hay que controlar y, en su condición de irregulares, expulsar). Las normas internacionales de "protección de la infancia" establecen que todo menor solo debe ser tutelado por el Estado, al encontrarse en situación jurídica de desamparo. De ahí que la 
mayoría de estos menores estén acogidos por las entidades públicas de protección de menores.

La categoría "menores no acompañados" inviabiliza y engloba una compleja realidad con la intención de sistematizar y homogeneizar a todo un colectivo que presenta una multitud de situaciones en las que se pueden encontrar. Esta pretendida uniformidad y categorización de todo un colectivo como "menores no acompañados" responde al interés de las instituciones, nacionales, comunitarias e internacionales, para denominar a una realidad que desde las instituciones nacionales, comunitarias e internacionales de protección fragmenta el marco jurídico, normativo e institucional, para poder clasificarla y gestionarla (Jiménez, 2011; Gimeno, 2013; Gimeno, 2014).

La llegada a la UE de los MENA evidencia las contradicciones de la política migratoria y de la política de asilo y refugio de la UE con los sistemas de protección de la infancia y la polémica sobre la externalización de las fronteras europeas. Estos "menores extranjeros no acompañados", desde su condición como menores y solicitantes de asilo, deben ser protegidos, y como extranjeros deben ser controlados.

En la literatura existen diversos términos que se utilizan como sinónimos para denominar a los menores de 18 años que no están bajo el cuidado de un adulto y que se encuentran en movimiento migratorio. Los más comunes son "niños no acompañados", "menores no acompañados" y "niños separados". ${ }^{4}$ Otros términos empleados, en este mismo contexto, son "solicitantes de asilo menores no acompañados" y "niños refugiados". Sin embargo, hay Estados y organismos internacionales que otorgan una particularidad a cada concepto.

Hay que señalar que en cada Estado de la UE, el tratamiento jurídico que se le da a esta categoría depende de las tradiciones y de las diferentes políticas en materia de migración y asilo. Los menores no acompañados reciben diferentes denominaciones dependiendo del Estado comunitario al que lleguen, produciéndose diferentes itinerarios y procesos de acogida que dependen de los flujos migratorios y la regulación de asilo que tengan estos países, por un lado, y de los propios sistemas de protección, por el otro.

Por todo lo anterior, es necesario definir al menor extranjero no acompañado desde el punto de vista legislativo. En la Resolución 97/C221/03 del Consejo de Europa de 26 de junio de 1997 (Diario Oficial no C221 de 19/07/2003, pp. 0023-0027) se estableció la definición de "menores no acompañados nacionales de terceros países" como:

4 Estos términos, aunque no incluyen palabra alguna que califique la condición migratoria, son también utilizados para describir la situación de algunos niños migrantes. 
Menores de 18 años, nacionales de países terceros, que llegan a territorio de los Estados miembros de la Unión Europea sin ir acompañados de un adulto responsable de ellos, ya sea legalmente o con arreglo a los usos y costumbres [del Derecho consuetudinario del Estado del que sea nacional el menor], en tanto no se encuentren efectivamente bajo el cuidado de un adulto responsable [por lo tanto, sin representación jurídica], así como aquellos menores que se queden solos tras su entrada en los Estados miembros (Diario Oficial n ${ }^{\circ} \mathrm{C} 221 \mathrm{de}$ 19/07/2003, p. 0023).

Después, el concepto de "menor extranjero no acompañado" se reconoció en varias Directivas de la UE en materia de extranjería: sobre protección temporal (Directiva 2001/55/CE del Consejo de 20 de julio de 2001), sobre condiciones de acogida (Directiva 2003/9/CE del Consejo de 27 de enero de 2003), sobre el derecho de repatriación familiar (Directiva 2003/86/CE del Consejo de 22 de septiembre de 2003), permiso de residencia a nacionales de terceros países (Directiva 2004/81/CE del Consejo de 29 de abril de 2004), sobre cualificaciones (Directiva 2004/83/CE del Consejo de 29 de abril de 2004, artículo 2, inciso i) y sobre los procedimientos (Directiva 2005/85/CE del Consejo de 1 de diciembre de 2005), incorporando la mención de los apátridas y el establecimiento de la edad de 18 años como referencia para la mayoría de edad. En la actualidad, la Directiva 2011/95/UE del Parlamento Europeo y del Consejo de 13 de diciembre de 2011 establece el término en el artículo 2, inciso 1:

El menor de 18 años no nacional de la UE o apátrida que llegue al territorio de los Estados miembros sin ir acompañado de un adulto responsable de él, ya sea legalmente o con arreglo a la práctica, mientras tal adulto no se haga efectivamente cargo de él; incluyendo al menor que deje de estar acompañado después de haber entrado en el territorio de los Estados miembros (Directiva 2011/95/UE).

En virtud de estas definiciones, los menores no acompañados se caracterizan por ser "apátridas" o "nacionales de otros países”, es decir, son naturales de Estados que no pertenecen a la UE. Quedan excluidos los menores comunitarios, que no se verían afectados por la restricción de libertad de circulación vigente para los nacionales de terceros Estados.

Por lo tanto, la protección del menor se basa, ante todo, en la identificación de la edad. En efecto, si el migrante es reconocido menor, generalmente puede ser asistido por un tutor o representante legal administrador ad hoc y disfrutar de ciertas 
medidas de seguridad ante las autoridades nacionales. Esta categoría restrictiva abarca solo a aquellos menores que llegan sin "un adulto responsable" que pueda hacerse cargo de ellos según lo que establezcan las leyes o los usos y costumbres. El carácter restrictivo del término "menor no acompañado" no refleja la realidad de estos menores que llegan a la UE; y la diversidad y complejidad de situaciones en las que se pueden encontrar es un principio básico que debe garantizar la atención de los menores.

Tres son las características definitorias de la condición del "menor extranjero no acompañado”: a) la minoría de edad, b) la ausencia de un adulto responsable y c) la condición de inmigrante. La intersección de estas condiciones define la singularidad jurídica del menor extranjero no acompañado, y los Estados deberán encargarse de adoptar las medidas necesarias para asegurar la protección del menor.

Las definiciones propuestas por Save The Children y ACNUR son las recogidas en el Derecho Internacional de los Derechos Humanos. Hay que señalar que, a pesar de que la Convención de los Derechos del Niño de 1989 no define lo que debemos entender por "menor no acompañado", el Comité de los Derechos del Niño - órgano de control de la Convención - sí se preocupa por el trato que reciben los menores que se encuentran en esta situación.

Durán (2011, p. 11) señala que la cuestión no es quién está al cuidado del menor, sino "si tiene cubiertas sus necesidades físicas y emocionales por adultos que sean responsables de su situación. El criterio de la falta de asistencia material o moral es el que se usa [...] para considerar que un menor está en situación de abandono y [...] debe quedar bajo la tutela de la Administración, sustrayéndose la patria potestad o la tutela a sus padres o tutores".

\section{Marco normativo internacional sobre la protección \\ de los menores extranjeros no acompañados}

La Declaración de los Derechos del Niño de 1959 (Resolución 1386 [XIV] de la Asamblea General de las Naciones Unidas) no se refiere de forma expresa a los MENA, aunque en su artículo 2 establece:

El niño gozará de una protección especial y dispondrá de oportunidades y servicios, dispensado todo ello por la ley y por otros medios, para que pueda desarrollarse física, mental, moral, espiritual y socialmente en forma saludable y normal, así como en condiciones de 
libertad y dignidad. Al proclamar leyes con este fin, la consideración fundamental a que se atenderá será el interés superior del niño.

Esta es la primera vez que se reconoció el principio del "interés superior del menor", principio fundamental que debe regir el ámbito de protección de los derechos del menor de edad.

La Convención de Naciones Unidas sobre los Derechos del Niño (CDN) de 20 de noviembre de 1989 no es un texto declarativo de principios genéricos, sino es un instrumento jurídico internacional vinculante para los Estados que lo hayan ratificado (Senovilla, 2010, p. 24). Esta CDN no prevé disposiciones especiales relativas a los niños migrantes, extranjeros, ni sobre los niños solicitantes de asilo, pero establece un amplio catálogo de derechos aplicables a los menores no acompañados como "el interés superior del niño" (artículo 3 de la CDN), que debe tenerse en cuenta en todas las decisiones concernientes a los menores.

Los 28 Estados miembros que conforman la UE han ratificado la CDN y reconocen, a través de este instrumento internacional, la necesidad de protección y cuidados especiales, y "el interés superior del menor, sin discriminación alguna" (artículo 2 de la CDN). En materia de menores no acompañados, el artículo 9.3 de la CDN menciona: "Los Estados Partes respetarán el derecho del niño que esté separado de uno o de ambos padres a mantener relaciones personales y contacto directo con ambos padres de modo regular, salvo si ello es contrario al interés superior del niño". En cuanto al "interés superior del niño", el artículo 18.1 señala:

Los Estados Partes pondrán el máximo empeño en garantizar el reconocimiento del principio de que ambos padres tienen obligaciones comunes en lo que respecta a la crianza y el desarrollo del niño. Incumbirá a los padres o, en su caso, a los representantes legales la responsabilidad primordial de la crianza y el desarrollo del niño. Su preocupación fundamental será el interés superior del niño.

Aquí cabe señalar que la concepción tuitiva del menor ha sido sustituida por una nueva y distinta percepción que le considera sujeto de derechos, tanto en el ámbito de la igualdad como en el ámbito de la libertad y de la seguridad. Por otro lado, es necesario mencionar la Observación General número 6 del Comité de Derechos

5 El principio del interés superior del niño está garantizado por la Convención de la Organización de las Naciones Unidas sobre los Derechos del Niño, y es el fundamento de todas las líneas de actuación en el ámbito europeo, aunque no siempre se respeta. 
del Niño de 2005, relativa al trato de los menores no acompañados y separados de sus familias fuera de su país de origen (CRC/GC/2005/6). En esta Observación, el Comité de Derechos del Niño hizo hincapié en que el disfrute de los derechos consagrados en la Convención no se limita a los niños del Estado parte, deben ser accesibles a todos los niños y el Estado parte debería proporcionar protección y asistencia a los niños no acompañados en su territorio. Los niños deben ser tratados como tales, con independencia de su nacionalidad o estatus migratorio, dice el Comité.

El nuevo paradigma sobre la infancia que introdujo la CDN influyó en la manera de tratar y considerar a los menores. El menor es, desde el punto de vista de la CDN, un sujeto en desarrollo, con derechos activos ${ }^{6}$ y pasivos.

En lo que a nuestro objeto de estudio se refiere, la $\mathrm{CDN}$ incluye la problemática y otorga un "estatuto particular a los niños refugiados". La CDN establece, en su artículo 20, el derecho de los MENA que están "temporal o permanentemente privados de su medio familiar a la protección y asistencia especial del Estado". Pero no prevé ninguna disposición de aplicación directa a los menores migrantes no acompañados. En su artículo 22, la CDN habla sobre la responsabilidad que tienen los Estados partes de establecer medidas de protección para los niños considerados como refugiados, así como para aquellos que traten de obtener tal estatuto, independientemente de estar o no acompañados de otra persona. Además de buscar la unificación de esfuerzos por parte de la Organización de las Naciones Unidas y de organizaciones no gubernamentales para poder reunir al menor con su familia, dicho artículo tiene como objetivo que los Estados partes adopten las acciones requeridas para que estos niños reciban una asistencia que les permita gozar de todos los derechos estipulados en la CDN y demás instrumentos internacionales de carácter humanitario y de derechos humanos.

A esta responsabilidad de cada Estado de velar por la aplicación del artículo 22 se le suman otros principios clave para dar un trato adecuado a los niños separados, como lo son favorecer la reunificación familiar (artículo 10 de la CDN), asegurar el derecho del niño a la vida, a la sobrevivencia y a su desarrollo (artículo 6 de la $\mathrm{CDN}$ ) y la protección del niño ante cualquier tipo de abuso, violencia y explotación (artículos 19, 32, 34, 35 y 36 de la CDN). Los Estados se comprometen a tomar todas las medidas necesarias para la readaptación física y psicológica de los niños que han sido víctimas de algún tipo de maltrato o negligencia (artículo 39 de la

\footnotetext{
${ }^{6}$ Los derechos activos son los siguientes: la libertad de conciencia, religión, pensamiento, libertad de expresión e información, libertad de asociación y reunión, el derecho de participación.
} 
CDN) y de otorgarle las condiciones necesarias para contar con el mejor estado de salud posible (artículo 24 de la CDN).

La CDN no solo busca "la protección de la vida del niño", sino además fomenta, a través de los artículos 12 y 13, que el niño sea escuchado y tomado en cuenta en la elaboración de su plan de vida, dependiendo, claro, de su edad y capacidades. Al dejar participar y tomar en cuenta la opinión de los niños separados, se puede comprender mejor su situación, lo cual permitirá crear estrategias que garanticen su desarrollo, que respondan a sus necesidades y que incluyan sus expectativas sociales, psicológicas y legales. Además, los Estados deben establecer protocolos de protección de los derechos de los menores en todas las fases del proceso migratorio, favoreciendo los mecanismos para el pleno desarrollo de su personalidad, ya sea a través de la reagrupación familiar o, en caso de que esta no sea posible, la integración del menor en el país de acogida (artículo 27 de la CDN).

Si bien la CDN busca proteger a los niños de un gran número de adversidades, y los Estados que forman la UE han aceptado el garantizar estos derechos, la realidad es diferente y la aplicación de los principios es limitada. Por un lado, se observa que en numerosas ocasiones, durante esta crisis migratoria, los niños migrantes son vistos primeramente como extranjeros, antes de ser vistos como niños. Para Senovilla (2014), "la noción de extranjero se construye sobre la base del criterio de nacionalidad" que cada Estado se reserva en atribuir en función de su soberanía y que justifica un tratamiento diferenciado y discriminatorio a los no nacionales.

Al no ser primordial la consideración de su estatuto específico de niño, estos niños con urgencia de protección quedan en una posición aún más vulnerable. Según lo estipulado en la Observación General no 14 del Comité de los Derechos de Niño de 2013 (CRC/C/GC/14), el “interés superior del niño" es un derecho, una regla que hay que tener en cuenta en todas las medidas concernientes a los niños. Por otro lado, a través del análisis del artículo 3 de la Convención, expuesto en el Manual de aplicación de la Convención sobre los derechos del niño para la UNICEF, de Hodgkin y Newell (2002), se observa que a pesar de ser un principio fundamental de la Convención, la noción del interés superior del niño lamentablemente es una noción imprecisa, que lo vuelve un elemento no medible, operacional y aplicable. El carácter vago de este concepto es un obstáculo para la búsqueda del bienestar del niño en todo momento, objetivo primordial de este artículo (UNHCR, 2006). El interés superior del niño puede depender de las experiencias vividas, la edad, el sexo, la madurez, la situación familiar, el ambiente, de sus circunstancias personales y familiares, entre otras. Para Horcas: 
La aplicación limitada de los principios y derechos de los menores "no acompañados" y la falta de concreción jurídica a la hora de respetar estos enunciados por parte de los Estados de la UE, ha provocado interpretaciones parciales que han originado situaciones de desprotección, maltrato institucional y vulneración de derechos a los menores que migran de manera independiente (2016, p. 27).

Stoecklin (2012), después de un análisis de los derechos y capacidades de los niños, llega a la conclusión de que los derechos de los niños son medios (o herramientas) únicamente para aquellos que los conocen y han comprendido que los pueden utilizar y hacer valer en ciertas circunstancias para alcanzar objetivos precisos. Es común que los niños refugiados o en búsqueda de asilo desconozcan completa o parcialmente sus derechos, por lo que, como lo menciona el Comité, es fundamental hacer del conocimiento de los niños sus derechos y servicios disponibles, así como cualquier información relacionada con el proceso de asilo, condición de la situación migratoria, entre otros. Al tener conocimiento pleno de esto, los niños se encuentran en mayor ventaja para hacer valer sus derechos.

\section{MARCO NORMATIVO COMUNITARIO SOBRE LA PROTECCIÓN DE LOS MENORES EXTRANJEROS NO ACOMPAÑADOS}

Como hemos podido ver en el segundo apartado de este trabajo, "menores extranjeros no acompañados" es una construcción social y jurídica que uniforma a todo un colectivo y nos impide ver la individualidad de cada uno de ellos, a pesar de que este colectivo ha sido definido por una variada regulación normativa de las instituciones europeas como de las de cada uno de los Estados miembros. Hay que señalar que ningún Tratado constitutivo comunitario había reconocido explícitamente el respeto de los derechos del niño. Era normal, ya que las Comunidades Europeas no tenían competencia directa ni sobre los niños ni sobre la familia, políticas y protecciones que son competencias nacionales. Habría que esperar al Tratado de Niza (2001) para que se mencionará a los niños en un Tratado comunitario, y se hace desde la cooperación policial en orden a la persecución de los delitos contra los niños (artículo 29 del Tratado de Niza).

La cuestión del asilo y refugio en Europa está regulada por el derecho nacional — de los 28 Estados miembros-, el Derecho Europeo y el Derecho Internacional Público - de los Derechos Humanos-. Según lo establecido en el marco del 
Derecho de la UE, la Carta de Derechos Fundamentales de la UE (en adelante, CDF de UE) prevé el derecho de asilo en su artículo $18 .^{7}$ El artículo 19 de la Carta prohíbe "el retorno de una persona a un Estado en el que corra un grave riesgo de ser sometido a la pena de muerte, tortura, $u$ otras penas o tratos inhumanos o degradantes". El artículo 47 de la misma Carta reconoce el "derecho a la tutela judicial efectiva y a un juez imparcial” (Diario Oficial de la UE, C 83 de 30.3.2010, pp. 395, 401)

Los 28 Estados miembros de la UE están obligados a regular sus actividades y operaciones en materia de asilo y refugio teniendo en cuenta la Convención de Ginebra sobre Refugiados de 1951 y su Protocolo de 1967, la Carta de Derechos Fundamentales de la Unión Europea (CDFUE) y el Convenio de Derechos Humanos. Además, respeta los estándares internacionales de la dignidad de las personas, la prohibición de la tortura, castigos, tratos inhumanos o degradantes, la libertad, los derechos de los niños, la prohibición de expulsión y devolución (non refoulement, artículo 33 de la Convención de Ginebra de 1951 y su Protocolo de 1967), y los principios de no discriminación, de proporcionalidad y el derecho a contar con un remedio judicial eficaz.

La UE ha ido creando una política común de asilo para que los solicitantes de asilo rechazados en un país no lo vuelvan a solicitar en otro país del espacio de Schengen. Esta política común se inició con la Convención de Dublín en 1990. Esta política continuó con la ejecución del archivo Eurodac y el Reglamento Dublín II en 2003, y permanece en la actualidad (en octubre de 2009 se adoptan dos propuestas de la Comisión Europea).

El Tratado de Funcionamiento de la Unión Europea (en adelante, TFUE) consolida la inmigración y el asilo como asuntos de seguridad interior del territorio de la UE, bajo el epígrafe "Espacio de libertad, seguridad y justicia" (título V). Al amparo de esta cartera, se continúan gestionando los flujos migratorios a través de una política común de inmigración, asilo y control de las fronteras exteriores (artículo 67.2 del TFUE), basada primordialmente en la prevención y lucha "reforzada" contra la inmigración "ilegal” (artículo 79.1 del TFUE), como presupuesto del espacio de seguridad al que se aspira. La política de asilo y refugio de la UE se apoya en el artículo 3(2) del Tratado de la Unión Europea (TUE) del Tratado de Lisboa (TdL) y en los artículos 67, 78-80 del TFUE, en el título V. En específico, el artículo 3(2) del TUE del TdL asienta:

7 El texto de este artículo se ha basado en el artículo 63 del Tratado CE, sustituido ahora por el artículo 78 del TFUE, que obliga a la UE respetar a la Convención de Ginebra sobre los Refugiados. 
La Unión Europea ofrecerá a sus ciudadanos un espacio de libertad, seguridad y justicia sin fronteras interiores, en el que esté garantizada la libre circulación de personas conjuntamente con medidas adecuadas en materia de control de las fronteras exteriores de asilo, inmigración y de prevención, y lucha contra la delincuencia (Diario Oficial de la UE, C 83 de 30.03 .2010 , p. 17).

Debemos señalar que la UE no tiene una competencia exclusiva y excluyente en materia de asilo y migraciones. Según lo estipulado en el artículo 4 II, j del TFUE (Diario Oficial de la UE, C 83, de 30.03.2010, p. 52), la UE tiene una competencia compartida de asilo y migraciones con los Estados miembros. Asimismo, de acuerdo con el artículo 78 del TFUE:

La Unión desarrollará una política común en materia de asilo, protección subsidiaria y protección temporal destinada a ofrecer un estatuto apropiado a todo nacional de un tercer país que necesite protección internacional y a garantizar el respeto del principio de no devolución. Esta política deberá ajustarse a la Convención de Ginebra de 28 de julio de 1951 y al Protocolo de 31 de enero de 1967 sobre el Estatuto de los Refugiados, así como a los demás tratados pertinentes (Diario Oficial de la UE, C 2007 115/47 de 26.10.2012, pp. 76-77).

La creación del "Espacio de Libertad, Seguridad y Justicia", contemplado en el título $\mathrm{V}$ del TFUE, exige el pleno respeto de los derechos fundamentales por parte de la UE y de todos los Estados miembros; y según el artículo 6 del TUE del TdL, la UE tiene la responsabilidad de respetar y hacer respetar los derechos fundamentales en todas sus acciones, con independencia de las competencias. El TFUE exige a la Unión que adopté:

[... medidas sobre asilo de acuerdo con la Convención de Ginebra de 1951 sobre el Estatuto de Refugiados que contemple, entre otras cuestiones, un estatuto uniforme de asilo válido en toda la Unión, un estatuto de protección subsidiaria, de procedimientos comunes parala concesión y retirada de dichos estatutos, criterios y mecanismos para determinar el Estado miembro responsable de examinar las solicitudes, normas relativas a las condiciones de acogida, y asociación y cooperación con terceros países.

En septiembre de 2008, la UE puso en marcha el Pacto Europeo sobre Inmigración y Asilo, que señala la necesidad de instaurar, a más tardar en 2012, el procedimiento de asilo único y el estatuto único para los refugiados y beneficiarios de protección 
subsidiaria. Para hacer frente a todo lo anterior, en 2010 se fundó la Oficina de Apoyo al Asilo (en adelante, EASO), que inició sus actividades a partir de 2011.

La EASO no creó una legislación de prácticas uniformes entre los países, pero la UE buscaba promover la cooperación entre los Estados de la UE en materia de asilo, por lo cual creó programas, proyectos y estrategias destinados a atacar el tráfico de personas e incrementar la atención hacia los menores en riesgo (European Plataform for Investing in Children, 2014).

El asilo en Europa quedó establecido en la Directiva sobre Requisitos de Reconocimiento (Directiva 2011/95/UE), en el que se establece la protección frente a la devolución. La UE trabajó desde entonces en la creación de un Sistema Europeo Común de Asilo (SECA). El SECA se basa en normas que determinan el Estado de la UE responsable de los solicitantes de protección internacional (incluida una base de datos de impresiones dactilares a efectos de asilo), estándares comunes para los procedimientos de asilo, condiciones de acogida, el reconocimiento y la protección de los beneficiarios de protección internacional. Además, respalda a los Estados miembros en la aplicación del mismo SECA para facilitar "el acceso al procedimiento de asilo a las personas necesitadas de protección; permitir la adopción de decisiones más justas, rápidas y acertadas; asegurar a quienes temen persecución que no se les devolverá a la situación de peligro; y, finalmente, ofrecer condiciones dignas y aceptables tanto a los solicitantes de asilo como a los beneficiarios de protección internacional dentro de la Unión" (Comisión Europea, 2014, p. 1)

En 2013 se establecieron nuevas normas para asegurar que el solicitante de asilo sea tratado de igual forma, con independencia del país de la UE en el que se formulase su solicitud. El marco normativo consta de los siguientes elementos:

a) El Reglamento de la UE n 604 /2013 del Parlamento Europeo y del Consejo (Reglamento de Dublín III). Este regula qué país de la UE debe aprobar una solicitud de asilo y refugio. Reglamento de la UE nº 603 /2013 del Parlamento Europeo y del Consejo (Diario Oficial de la Unión Europea L 180 de 26.6.2013; Reglamento EURODAC), que crea una base de datos con huellas dactilares de asilados y refugiados y de apátridas que buscan refugio en la UE. La Directiva 2011/95/UE del Parlamento Europeo y del Consejo (Directiva de Calificación), que establece normas sobre la acogida de nacionales de terceros países y apátridas que piden protección internacional.

b) Directiva 2013/33/UE refundida sobre condiciones de acogida del Parlamento Europeo y del Consejo (Diario Oficial de la UE, L 180 de 29.6.2013; Directiva 
de Acogida de Asilo —artículo 13 (revisión médica) y artículo 29 (personal y recursos) —, que rigen a partir del 21.7.2015), que regula el trato a las personas que piden protección internacional. Esta Directiva 2013/33/UE contempla la acogida de solicitantes, teniendo en cuenta el régimen especial establecido en el caso de "los menores no acompañados", donde prima el interés superior del menor. Una vez en territorio de la UE, el artículo 9.1 de la Directiva 2013/32/ UE establece que la presencia del solicitante de asilo en el territorio de un Estado miembro es legal y que además se le debe conceder al solicitante documentación que pruebe su estatus (artículo 6 de la Directiva 2013/33/UE).

c) Directiva 2013/32/UE del Parlamento Europeo y del Consejo (Diario Oficial de la UE, L 180 de 29.6.2013) sobre procedimientos comunes para la concesión o la retirada de la protección internacional. Establece los estándares comunes para el reconocimiento o rechazo de protección internacional, con la finalidad de eliminar las diferencias que presentan los Estados miembros de la UE en este aspecto.

d) Directiva 2008/115/CE del Parlamento Europeo y del Consejo (Diario Oficial de la UE, L 348 de 24.12.2008), relativa a normas y procedimientos comunes en los Estados miembros para el retorno de los nacionales de terceros países en situación irregular en territorio de la UE.

\section{LOS DERECHOS DE LOS MENORES EXTRANJEROS NO ACOMPAÑADOS QUE SOLICITAN ASILO EN LA UNIÓN EUROPEA}

En la UE no existe en la actualidad un sistema de protección de niños no acompañados solicitantes de asilo que sea claro y general. La protección de los derechos del niño se incorporó en el TdL, según lo estipulado en el artículo 3.3 del TUE de Lisboa, en el que establece que "la Unión combatirá la exclusión social y la discriminación y fomentará la justicia y la protección sociales, la igualdad entre mujeres y hombres, la solidaridad entre las generaciones y la protección de los derechos del niño" (Diario Oficial de la UE, C 83, 30.03.2010, p. 17).

La protección de los derechos del menor es uno de los objetivos de la UE, según el artículo 3, apartado 3, del TUE de Lisboa, que exige a la UE "fomentar la protección de los derechos del niño”, a pesar de que los derechos fundamentales del menor están plasmados en el artículo 24 de la CDFUE, en el que se reconoce que los niños son titulares independientes y autónomos de derechos: 
1. Los menores tienen derecho a la protección y a los cuidados necesarios para su bienestar. Podrán expresar su opinión libremente. Ésta será tenida en cuenta en relación con los asuntos que les afecten, en función de su edad y de su madurez.

2. En todos los actos relativos a los menores llevados a cabo por autoridades públicas o instituciones privadas, el interés superior del menor constituirá una consideración primordial.

3. Todo menor tiene derecho a mantener de forma periódica relaciones personales y contactos directos con su padre y con su madre, salvo si son contrarios a sus intereses (Diario Oficial de la UE, C 83 de 30.3.2010, pp. 389-403).

El artículo 24.2 de la CDFUE señala que "En todos los actos relativos a los menores llevados a cabo por autoridades públicas o instituciones privadas, el interés superior del menor constituirá una consideración primordial”. En el artículo 24.3 añade: "Todo menor tiene derecho a mantener de forma periódica relaciones personales y contactos directos con su padre y con su madre, salvo si son contrarios a sus intereses". Si bien es importante destacar el avance en el reconocimiento de los derechos de los menores, también hay que señalar que ni la CDN ni el Convenio Europeo de Derechos Humanos (CEDF) ofrecen una definición exhaustiva sobre el interés superior del menor. Aun así, con base en los tratados anteriormente citados, podemos establecer algunas pautas para tener claridad sobre la dimensión de dicho concepto. Los derechos reconocidos en el artículo 24 de la CDFUE están reconocidos en la CDN, como se puede apreciar en el apartado anterior, y estos son "inherentes a la dignidad humana, y se desarrollan en otras normas nacionales, europeas o internacionales”.

Las normas consideradas destacan la importancia de la relación entre los padres y el niño. En este sentido, podemos decir que el interés superior del niño es vivir, desarrollarse, crear su propia dignidad humana en el entorno familiar — siempre y cuando existan las condiciones suficientes-. No debemos olvidar que las circunstancias para que el menor viva en un entorno apto para su crecimiento no dependen solo y exclusivamente de los padres, sino también del contexto social en que tendrá que independizarse. Es por eso que el interés superior del niño, sin previamente reconocer derechos básicos como la educación, la vivienda, el acceso a un sistema sanitario - entre otros-, se dimensiona y se vuelve un gran desafío. La regulación internacional de la protección del MENA que se encuentra fuera de su país de origen se apoya sobre el principio jurídico “interés superior del 
menor". Este interés superior, en principio, se identifica por parte de la doctrina y la jurisprudencia nacional e internacional con la reagrupación familiar en el país de origen (Pérez, 2008). El MENA es, entonces, en el país de destino un extranjero en situación irregular y puede ser repatriado a su país.

El Convenio Europeo de Derechos Humanos no contiene disposiciones referentes a los "menores extranjeros no acompañados", pero el trato de estos se puede considerar a partir de diferentes disposiciones, como el artículo 5, sobre "el derecho a la libertad y a la seguridad"; el artículo 8, sobre "el derecho al respeto a la vida privada y familiar", o el artículo 2 del Protocolo número 1 , sobre el derecho a la educación. El Tribunal Europeo de Derechos Humanos ha sostenido que los Estados miembros tienen la responsabilidad de asistir a los MENA y no abandonarlos cuando son liberados de una detención.

No hay que olvidar que el "menor extranjero no acompañado" es primero un niño; por lo tanto, debe beneficiarse de todos los derechos formulados en la CDN. ${ }^{8}$ El dispositivo previsto para toda la UE tiene como objetivo reafirmar o complementar algunas disposiciones de la referida Convención. Con este fin, el artículo 3 de la Resolución del Consejo de Europa de 26 de junio de 1997 sugiere la adopción de unas garantías mínimas para todos los menores no acompañados: el derecho a la identidad, la protección, la atención básica y la reunificación familiar.

En el marco de la Unión Europea, debemos destacar los siguientes documentos sobre los menores extranjeros no acompañados: a) Resolución del Parlamento Europeo de 12 de septiembre de 2013 (2012/2263[INI]) "Sobre la situación de los menores extranjeros no acompañados en la Unión Europea”, en la que se reconoce la dispersión normativa en relación con la protección de este colectivo, subrayando la necesidad de aprobar una normativa de mínimos común y coherente; b) Comunicación de la Comisión de las Comunidades Europeas "Hacia una estrategia de la Unión Europea sobre los derechos de la infancia”, de 4 de julio de 2006 (COM, 2006, 367 final), basada en lo dispuesto en la Observación General núm. 6 de 2005 del Comité de Naciones Unidas sobre los Derechos del Niño, relativa al "Trato de los menores no acompañados y separados de sus familias fuera de su país de origen” (39 periodo de sesiones, de 17 de mayo al 3 de junio de 2005), en la que se señala la necesidad de establecer una estrategia comunitaria global para proteger de manera efectiva los derechos de la infancia; c) el Plan de acción sobre los menores no acompañados (2010-2014) (COM, 2010,

8 Derechos que se proporcionan del artículo 2 al artículo 40 de la Convención Internacional sobre los Derechos del Niño. 
213 final de 6 de mayo de 2010), que reconoce que no existen "datos completos, fiables y comparables”, por lo que señala que sería conveniente que las estadísticas abarcaran a todos los MENA, no solo a los que solicitan asilo; d) el Programa de Estocolmo del Consejo Europeo. Una Europa abierta y segura que sirva y proteja al ciudadano (2010/C115/01), aprobado por el Consejo Europeo de 10 y 11 de diciembre de 2009.

En el marco del Consejo de Europa, debemos mencionar los siguientes documentos: a) Resolución 1810 (2011) de 15 de abril de 2011 de la Asamblea Parlamentaria del Consejo de Europa, "Menores migrantes indocumentados en situación irregular: Un motivo real de preocupación”; b) Recomendación 1985 (2011) de 7 de octubre de 2011 de la Asamblea Parlamentaria del Consejo de Europa, "La prolongada llegada de migrantes irregulares, solicitantes de asilo y refugio a las orillas de Europa del Sur”; c) la Recomendación 1969 (2011) de 15 de abril de 2011, "Menores no acompañados en Europa: Problemas relativos a la llegada, estancia y retorno"; d) Recomendación 1703 (2005) "sobre protección y asistencia para menores solicitantes de asilo”; e) Recomendación 1596 (2003) “sobre la situación de los jóvenes migrantes en Europa".

La Resolución 1810 (2011) aborda cuestiones relacionadas con la llegada, estancia y retorno de los MENA en Europa. Ofrece derechos y garantías a estos migrantes, entre los que se encuentran el respeto por el menor de edad, la primacía del interés superior del menor, la prohibición de devolución, el acceso a los procedimientos de asilo, la prohibición de la retención de los niños migrantes, soluciones duraderas y la reunificación. Este último hace hincapié en que el carácter humanitario debe prevalecer en el tratamiento de los MENA. Con este fin, se establece que los Estados deben prestar más atención a la protección de los MENA en el control de la inmigración. Esta protección debe ser mayor cuando la estancia del menor se prolonga o es víctima de abandono, explotación, tortura o tratos crueles, inhumanos o degradantes.

La Resolución 1895 (2011) de la Asamblea Parlamentaria señala la necesidad de establecer y reforzar los instrumentos para que se lleve a cabo una protección efectiva de estos derechos, proponiendo la elaboración de un documento base o una guía de buenas prácticas en relación con las condiciones de detención de los menores.

La Recomendación 1969 (2011) de la Asamblea Parlamentaria advierte de la necesidad de elaborar una guía de principios y directrices en la materia, iniciativa que fue paralizada por el Comité de Ministros, esto es, por los gobiernos de los Estados de la UE. 


\section{Plan de aCción de la Unión EuRopea}

\section{PARA LOS MENORES NO ACOMPAÑADOS (2010-2014)}

Sucesores del Programa de Tamperé (2000-2005) de octubre de 1999 fueron el Programa de La Haya (2005-2010) (Diario Oficial de la UE, C 198, de 12 de agosto de 2005) y el Programa de Estocolmo (2010-2014) (Diario Oficial de la UE, C 115, de 4 de mayo de 2010). En el Programa de Estocolmo se definieron las orientaciones estratégicas de la programación legislativa y operativa en el espacio de libertad, seguridad y justicia de la UE, partiendo de los logros de los anteriores programas, pero teniendo en cuenta los nuevos desafíos que debe afrontar Europa con un enfoque global.

En 2009, el Programa de Estocolmo del Consejo de Europa por primera vez señaló el propósito de promover y proteger "los derechos de los menores en situación de vulnerabilidad, como aquellos víctimas de explotación sexual y maltrato, así como a las víctimas de la trata y a los menores no acompañados"; y establece medidas de prevención, protección, asistencia y retorno que contemplen el interés superior del menor.

El Programa de Estocolmo señaló la necesidad de dar una respuesta global en el nivel comunitario y reclamó la atención para los MENA en el contexto de la política de inmigración de la UE. Los derechos enunciados son los siguientes: "el principio de que el mayor interés del niño es el derecho del niño a la vida, la supervivencia y el desarrollo, la no discriminación y el respeto por el derecho de los niños a expresar sus opiniones y ser genuinamente escuchados en todos los asuntos que les afecten según su edad y nivel de desarrollo" (Diario Oficial de la UE, 2010/C 115/09). Introdujo un subapartado para los MENA, como grupo particularmente vulnerable que necesita de una atención especial y respuestas específicas, intercambio de información, y mejores prácticas; la introducción ilegal de menores; "la cooperación con los países de origen, las cuestiones de la determinación de la edad, la identificación y la búsqueda de la familia, y la necesidad de prestar particular atención a los menores no acompañados en el contexto de la lucha contra la trata de seres humanos" (Diario Oficial de la UE, 2010/C 115/031).

El Programa de Estocolmo (2010-2014) pidió a la Comisión que examinará "las medidas prácticas para facilitar el retorno del elevado número de menores no acompañados que no requieren protección internacional" (Diario Oficial de la UE, 2010/C 115/01). El análisis realizado en el marco del Programa de Estocolmo sobre los MENA instó a la Comisión y a los Estados miembros a priorizar la condición 
de extranjeros, más que de sujetos de protección, priorizando leyes de inmigración que focalizan unas medidas en impedir su entrada y en su repatriación, buscando complicidades con los países de origen a través de la cooperación al desarrollo.

Hay que señalar que el análisis mostró que la solución no podía limitarse al retorno - que era solo una de las posibles opciones - porque la cuestión era mucho más compleja y multidimensional, y existían límites claros a la libertad de acción de los Estados de la UE para tratar a los MENA. En mayo de 2010, la Comisión Europea presentó el Plan de acción para los menores no acompañados (2010-2014) (COM, 2010, 213 final) que considera a los MENA como las víctimas más vulnerables de la migración; en él se abordan diversos aspectos prioritarios de la UE en el tratamiento de los MENA, completando la estrategia de control del Programa de Estocolmo.

El Plan de acción de la UE para los menores no acompañados (2010-2014) es el primer paso por parte de la UE para establecer una estrategia global en el tratado de los MENA, a pesar de no ser vinculante para los Estados miembros. El enfoque común de este Plan se basa en el respeto de los derechos del niño establecidos en la CDFUE y en la CDN, teniendo como principio rector el interés superior del menor. Además, tenía como objetivo "armonizar y buscar soluciones duraderas para los MENA, basadas en la recepción, la protección, integración de estos, la cooperación con terceros países en materia de retorno, reintegración y prevención de la inmigración infantil".

En el Plan de acción se enumeran las directrices para la acogida de los menores, y pone énfasis en la tutela y en la representación legal, dejando claro que se debe tener en consideración el interés superior del menor, los Estados miembros deben ofrecerles la protección internacional o el reasentamiento en la UE. El Plan de acción establece tres vías de acción principales: 1) prevención, 2) programas regionales de protección y 3) recepción e identificación de soluciones duraderas (retorno, integración, reasentamiento). Estas vías ocasionan incoherencias con aspectos como la no repatriación y con el interés superior del menor. El Plan de acción responde a la insistencia del Consejo Europeo de facilitar el retorno a los MENA, señalando que el retorno es solo una de las tres soluciones duraderas posibles - junto con la integración en el Estado miembro, y/o en el caso de solicitantes de asilo, el reasentamiento-, entre las cuales se habrá de optar de manera individualizada en función de lo que dicte el interés superior del menor. Lo que transformó el retorno de los MENA en una solución duradera como forma de protección al menor. Como complemento a este Plan, la Red Europea de Migración realizó un amplio estudio en la UE acerca de las políticas de acogida y de los acuerdos de devolución y de integración de los MENA. 


\section{El Reglamento de Dublín III}

El Reglamento Dublín III (Reglamento [UE] nº 604/2013 del Parlamento Europeo y del Consejo) entró en vigor el $1^{\circ}$ de enero de 2014. Realizó modificaciones al anterior Reglamento de Dublín II (Reglamento [UE] n 343/2003 de 18 de febrero de 2003), y se establecieron los criterios y mecanismos de determinación del Estado miembro de la UE competente para examinar una solicitud de asilo presentada por un nacional de un país tercero. Los criterios para establecer esta responsabilidad son, en orden jerárquico, las consideraciones de la familia, la posesión de un visado o permiso de residencia en un Estado miembro, la entrada regular o irregular del solicitante de asilo en la UE. El Reglamento Dublín III es uno de los pilares esenciales en el marco normativo de la protección internacional de los refugiados y la protección subsidiaria ante la actual crisis migratoria porque establece los mecanismos que determinan qué Estado será responsable de alguna solicitud de asilo presentada por un solicitante de un tercer país o apátrida, además establece una base de datos de huellas dactilares, llamada EURODAC, con el objetivo de evitar el abuso del sistema y el reenvío de los solicitantes de un país miembro a otro. Uno de los principales cambios en el Reglamento Dublín III es que les exenta de la obligación de que su solicitud sea procesada en el Estado de llegada, en caso de que se den ciertas circunstancias por las que se solicite su permanencia en o traslado a otro Estado.

A pesar de instrumentos como la Comunicación de 2011 "Una Agenda de la UE en pro de los Derechos del Niño" (COM, 2011, 60 final), como tantas veces en el ámbito europeo, al no contar la UE con competencia en materia de menores, esta protección y garantías dependerán de la voluntad de los Estados miembros, e incluso de los condados, comunidades autónomas, regiones y municipios. Es paradójico que el sistema de protección a la infancia de dichas administraciones territoriales, tan reglamentado, haría inviable cualquier iniciativa privada para ayudar a este colectivo.

El programa de la Comisión para los derechos del niño pretende que todas las políticas de la UE que tengan repercusión sobre los niños respeten sus derechos. Define los principios y objetivos de la UE en ese ámbito y presenta once acciones que la Comisión llevará a cabo en los próximos años. ${ }^{10}$ El Reglamento de Dublín III

\footnotetext{
9 El Reglamento de Dublín se aplica en toda una región geográfica, que abarca 32 países: los 28 Estados de la UE y cuatro países asociados al Reglamento de Dublín (Islandia, Liechtenstein, Noruega y Suiza).

10 "LaUEpropone once acciones cuyo objetivo es promover y proteger los derechos del niño:a) adoptar una propuesta de Directiva que incremente el nivel de protección de las víctimas vulnerables, incluidos los niños; b) presentar
} 
( $n^{\circ}$ 604/2013) introduce un mecanismo de alerta temprana, preparación y gestión de una crisis; disposición sobre la protección de asilo, como la entrevista personal obligatoria, garantías de los menores (incluyendo la descripción de los factores que deben sustentar la evolución del menor) y las posibilidades de reunificación familiar, la posibilidad de que la apelación de un recurso tenga efecto suspensivo sobre la ejecución de la transferencia durante el periodo de aplicación para el periodo durante el cual la aplicación sea considerada, junto con la garantía del derecho a permanecer en el territorio en espera de una decisión judicial sobre la suspensión de la apelación de transferencia; la obligación de garantizar la asistencia jurídica gratuita bajo petición; la reducción de los motivos de internamiento, así como la estricta limitación de la duración de la detención; la posibilidad de que los solicitantes de asilo, que en algunos casos pueden ser considerados inmigrantes ilegales, y los repatriados en aplicación de la repatriación, para ser tratados en el marco del procedimiento de Dublín, ofreciéndoles una mayor protección en la repatriación; la obligación de garantizar el derecho de apelar la decisión de ser transferidos; aclarar los procedimientos entre los Estados miembros, con los plazos establecidos.

El Reglamento Dublín III ${ }^{11}$ también incluye garantías que se aplican a todos los menores sujetos al "procedimiento de Dublín” durante el proceso de solicitud de asilo. Según lo establecido en el Reglamento de Dublín III (n 604/2013), las solicitudes de los MENA deberán ser examinadas por el Estado miembro en el que se encuentre legalmente un miembro de la familia, un hermano o un pariente del menor (artículo 8). Se les deberá asignar un representante (artículo 6). El artículo 6.3

una propuesta de Directiva que establezca salvaguardas especiales para las personas sospechosas en situación de vulnerabilidad, incluidos los niños; c) revisar la legislación que facilita el reconocimiento y la ejecución de las decisiones en materia de responsabilidad parental; d) promover los principios rectores del Consejo de Europa sobre justicia accesible a los niños y tomarlos en consideración en la elaboración de la legislación civil y penal; e) apoyar la formación de los jueces y otros profesionales para favorecer una participación óptima de los niños en los sistemas judiciales; f) mejorar la formación de las autoridades que atiendan a los menores procedentes de terceros países no acompañados por un adulto a su llegada al territorio de la UE; g) prestar atención a los niños en el marco de las medidas que los Estados miembros adoptarán en favor de la integración de los gitanos; h) promover la rápida introducción de la línea directa europea 116.000 para niños desaparecidos y la creación de mecanismos de alerta de desaparición de menores; i) adoptar medidas en el marco del Programa de la UE 'Safer Internetcontra el acoso, la manipulación psicológica con fines sexuales, la exposición a contenidos nefastos y el resto de riesgos a los que se exponen los niños internautas; $\mathrm{j}$ ) aplicar las Orientaciones de la UE relativas a la promoción y la protección de los derechos del niño en sus relaciones con terceros países, así como las Directrices sobre los niños y los conflictos armados; $\mathrm{k}$ ) crear un punto único de acceso destinado a los niños en la página web Europa en el que puedan acceder a información sobre la Unión y sus derechos".

11 Estados miembros, incluidos el Reino Unido, Irlanda y Dinamarca (en virtud de un acuerdo internacional celebrado en 2006 entre la Comunidad Europea y Dinamarca), así como en los cuatro países no pertenecientes a la UE que participan en el régimen de Schengen (Islandia, Noruega, Suiza y Liechtenstein). 
orienta sobre cómo determinar el interés superior del niño. El artículo 11 contiene normas para evitar la separación, como consecuencia de la aplicación del Reglamento de Dublín III, en caso de que los miembros de la familia presenten solicitudes separadas en un mismo Estado miembro. A falta de un miembro de la familia, un hermano o un pariente, el Estado miembro responsable será aquel en el que el menor haya presentado la solicitud de asilo, siempre que ello redunde en el interés superior del menor (artículo 8).

Debido a que los MENA forman una categoría de personas vulnerables, es bueno no prolongar más de lo necesario el procedimiento para determinar el Estado miembro responsable, lo que implica, en principio, que los MENA no sean trasladados a otro Estado miembro. En interés de los MENA, es útil no alargar el procedimiento de determinación del Estado miembro responsable, sino garantizar el acceso rápido a los procedimientos para determinar la condición de refugiado.

El programa de la Comisión para los derechos del niño pretende que todas las políticas de la UE que tengan repercusión sobre los niños respeten sus derechos. Define los principios y objetivos de la UE en ese ámbito y presenta once acciones que la Comisión llevará a cabo en los próximos años. El Reglamento Dublín III pone el mayor peso del problema en países fronterizos como España, Italia y Hungría. Los problemas que enfrentan son aún mayores: en Grecia, la Policía Helénica se encarga de recolectar los datos de los menores y de atender las demandas de asilo; sin embargo, las autoridades helénicas no están capacitadas para tratar a los grupos vulnerables de migrantes, esto aunado a que el país es un principal punto de llegada utilizado en su mayoría solo como país de tránsito, los MENA terminan siendo tratados como criminales que intentan entrar ilegalmente al país (SPANDA Foundation, 2014, pp. 20-21).

Por ejemplo, en España, aunque los flujos de los MENA no son un fenómeno nuevo, presenta muchos obstáculos para los menores solicitantes de asilo, quienes al aplicar para obtener el estatus de refugiado esperan hasta nueve meses a que se resuelva su situación, y si se considera imposible la repatriación, los menores pueden entonces solicitar la residencia (SPANDA Foundation, 2014, pp. 35-36). Proteger a los MENA es el deber de los Estados comunitarios, no es una opción; por eso deben actuar con eficacia y con respeto a los derechos de los niños, ya que la condición del niño es la que importa, no la de migrante.

Por primera vez desde el inicio de la crisis de refugiados en Europa, hay más niños y mujeres que llegan a Europa que hombres. Italia registró 8461 menores solo en 2013. Los MENA llegan a ese país por las oportunidades y condiciones 
socioeconómicas que les presenta, pero muchos de estos menores han desaparecido (SPANDA Foundation, 2014, pp. 23-24). Se calcula que en 2015 se perdieron en Italia cerca de cinco mil menores, según datos de la Europol (ElEconomista.es, 31 de enero de 2016).

\section{CONSIDERACIONES FINALES}

La crisis de refugiados y migrantes actual es diferente a cualquier otra, y plantea retos únicos a los programas para niños y familias que están viajando, ya que a veces pasan unas horas en los centros de tránsito. Los patrones de actuación de la UE relativos a los MENA son adoptados en virtud de la Carta de los Derechos Fundamentales de la UE (2000) y la Convención sobre los Derechos del Niño de las Naciones Unidas (1989). El problema tiene muchas aristas y directrices, mas todas convergen en un solo punto esencial: la necesidad de armonizar la terminología de “menores no acompañados", ya que únicamente comprendiendo este fenómeno de la misma manera los diferentes países de la UE podrán contar con estadísticas más claras y concisas y estarán en facultad para dar respuestas y soluciones adecuadas que otorguen la protección que cada menor necesita, como la homogeneización de las políticas de asilo.

Las instituciones europeas podrían argumentar que no estaba prevista una situación como la presente cuando se elaboró la política común en materia de menores extranjeros no acompañados. La doble condición de los MENA como inmigrantes irregulares solicitantes de asilo y menores de edad les vuelve más vulnerables que los demás refugiados, hallándose entre la normativa de extranjería y la de protección jurídica de la infancia, por lo que la política de asilo debe homogeneizarse. Sin embargo, no deberían faltar herramientas para su protección si tenemos en cuenta que en el ámbito comunitario toda la legislación que les afecta está incluida en el Sistema Europeo Común de Asilo (SECA), siempre bajo las directrices del ACNUR.

A pesar del conocimiento en derechos humanos y derechos de los niños, son varias las barreras que se presentan y se incrementan a medida que también aumentan los flujos migratorios. Desde barreras lingüísticas y personal poco capacitado que no se da abasto hasta limitaciones en la agilidad de los procesos, por lo que es imprescindible hacer valer el derecho 12 , tomando en cuenta la opinión de los niños con el fin de comprender su situación y sus expectativas para la creación de planes que salvaguarden su integridad física y psicológica. 
Los desafíos que plantean los MENA superan las obligaciones de la UE respecto de los mayores de edad. Las medidas básicas a tener en cuenta son: la protección inmediata por parte de las autoridades del Estado, en caso de que la edad de la persona no sea cuestionada; la prohibición de aplicarles la detención administrativa, a pesar de que se está aplicando, principalmente en el Reino Unido y Grecia; el acceso a un bienestar básico y a la educación, que no suele hacerse efectivo hasta que se formalice una solución duradera; la designación de un tutor, que se cumple en escasas ocasiones, y el acceso a la justicia, que no está garantizado.

La inexistencia de un sistema internacional capaz de rastrear y dar seguimiento a los menores es tan evidente como la falta de coordinación en las políticas y la gestión de los países miembros de la UE, ya que no existen bancos de datos que contengan la cantidad exacta de menores solicitantes de asilo y refugiados; muchos de ellos se encuentran desaparecidos, y las autoridades suponen que han sido captados por las mafias, han fallecido o han abandonado el país al que llegaron para ir a otro que les proporcione mejores oportunidades, como Alemania. La realidad es que el reglamento Dublín III, además de poner la mayor parte del peso del problema en los países fronterizos de Europa, como Grecia, Italia o Hungría, obstaculiza la reunificación familiar en tiempos breves y elegir dónde vivir.

Es indispensable que todos los países miembros, en especial aquellos países fronterizos que reciben la mayor cantidad de solicitantes de asilo, regulen las medidas de seguridad para los migrantes en tránsito en puertos, aeropuertos y fronteras desprotegidas, creando un sistema de recopilación de datos de cada migrante que ingresa a la UE en busca de asilo, en especial de los menores, lo cual ayudaría a dar seguimiento de su paradero y su situación humanitaria. Además de tener la posibilidad de proteger a los menores que buscan asilo internacional asegurando sus derechos humanos en la UE mediante la cooperación y armonización de políticas, la acción de la UE en los países de origen de estos menores también es indispensable para disminuir los conflictos y por ende el flujo migratorio. A pesar de todo, parece que los esfuerzos de la UE se han incrementado y están inclinándose hacia un nuevo camino en materia de la legislación sobre el asilo y la migración con una perspectiva más concreta y holística hacia los derechos de los niños y menores. 


\section{BibLIOgRAFÍA}

Abellán, L. (12 de mayo de 2015). Las concesiones de asilo en la UE aumentan un 50\% en un solo año. El País. Recuperado de http://internacional.elpais.com/internacional/2015/05/12/actualidad/1431428672_851768.html.

Claro Quintáns, I., y Lárazo González, I. (coords.) (2013). Infancia y protección internacional en Europa. Niños y niñas refugiados y beneficiarios de protección subsidiaria. Madrid, España: Tecnos.

Comisión Española de Ayuda al Refugiado (2015). Informe 2015: Las personas refugiadas en España y Europa. Madrid, España: Comisión Española de Ayuda al Refugiado. Recuperado de http://www.cear.es/wp-content/uploads/2015/06/Informe-2015de-CEAR3.pdf.

Consejo Europeo sobre Refugiados y Exiliados (2009). Comparative Study on Practices in the Field of Return of Minors: A Checklist to Achieve Good Practices When Considering the Return of Children to Third Countries. A Tool for Quality Planning for Member States. Bruselas, Bélgica: European Council on Refugees, Exiles and Save the Children. Recuperado de HOME/2009/RFXX/PR/1002.

Durán Ruiz, F. J. (2011). Los derechos de los menores no acompañados inmigrantes y solicitantes de asilo en la Unión Europea de las fronteras fortificadas y sus Estados miembros. TRACE, 60(diciembre): 9- 17. Recuperado de https://trace. revues.org/1723.

ElEconomista.es (31 de enero de 2016). Al menos 10.000 niños refugiados han desaparecido tras llegar a Europa. Recuperado de http://ecodiario.eleconomista.es/europa/ noticias/7316895/01/16/Al-menos-10000-ninos-refugiados-han-desaparecidotras-llegar-a-Europa.html.

European Platform for Investing in Children (2014). Unaccompanied Minors and Child Protection in Europe. Bruselas, Bélgica: European Comission, Directorate General for Employment, Social Affairs and Inclusion. Recuperado de http://europa.eu/ epic/news/2014/20140603-unaccompanied-minors-child-protection_en.htm.

Gimeno, C. (2013). Jóvenes que migran solos. Actores y escenarios fuera de los sistemas de protección de menores. Alternativas. Cuadernos de Trabajo Social, 20: 41- 56. DOI: 10.14198/ALTERN2013.20.03.

Hodgkin, R., y Newell, P. (2002). Manual de aplicación de la Convención sobre los Derechos del Niño. Nueva York, Estados Unidos: Fondo de las Naciones Unidas para la Infancia. Recuperado de http://www.unicef.es/sites/www.unicef.es/files/ Manual_cdn.pdf. 
Horcas López, V. (2016). Entre el controly la protección. Los dispositivos de atención de los menores migrantes no acompañados (MMNA) en el País Valencià (tesis doctoral). Universidad de Valencia, Valencia, España. Recuperado de http://roderic.uv.es/ bitstream/handle/10550/50818/Tesis\%20definitiva.\%201.02.16.pdf?sequence=1.

JimÉnEZ, M. y Vacchiano, F. (2011). De “dependientes” a “protagonistas”. Los menores como sujetos migratorios. En N. Ribas Mateos (ed.). El Río Bravo Mediterráneo. Las regiones fronterizas en la época de la globalización (pp. 495-511). Barcelona, España: Editorial Bellaterra.

LÁZA Ro, I. E., y Moroy, B. (eds.) (2010).Losmenores extranjeros no acompañados. Madrid, España: Tecnos.

Moraga Klener, C. (2015). Política de asilo y refugio de la Unión Europea. ¿La protección internacional como un "golpe de suerte". Revista de Derecho Público, 82(primer semestre): 143-164. Recuperado de http://repositorio.uchile.cl/bitstream/handle/2250/134647/Politica-de-asilo.pdf?sequence=1\&isAllowed=y.

Ortega Terol,J.M.(2006).Elasiloyel refugioenlaUniónEuropea:Crónicadeunamorausente. CursosdeDerechos HumanosdeDonostia-San Sebastián, VI:55-65. Recuperado de http://www.uma.es/investigadores/grupos/incodeum/Archivos/DDHH/ El\%20asilo\%20y\%20el\%20refugio\%20en\%20la\%20Union\%20Europea.pdf.

PÉrez, M. C. (2008). Interés superior del menor y retorno de los menores no acompañados a su país de origen. En Consejo Superior de Investigaciones Científicas. II Jornadas sobrepoliticas migratorias, justicia y ciudadania. Madrid, España: Consejo Superior de Investigaciones Científicas.

Programa para los Derechos del Niño (2012). La Unión Europea y los derechos de los Niños. Síntesis del documento Una Agenda de la UE en pro de los Derechos del Niño. Última modificación 14/06/2012. Recuperado de http://eur-lex.europa. eu/legal-content/ES/TXT/HTML/?uri=URISERV:dh0006\&from=ES.

Senovilla Hernández, D. (2010). El tratamiento de losmenores extranjeros no acompañadosy separados en Europa. Un estudio comparado de seispaises (tesis doctoral). Universidad Pontificia Comillas. Madrid, España.

Senovilla Hernández, D. (2012). El plan de acción (2010-2014) de la Comisión Europea. ¿Un verdadero avance de las políticas comunitarias relativas a los menores no acompañados? Revista Mugak, 56. Recuperado de http://mugak.eu/revistamugak/no-56/el-plan-de-accion-2010-2014-de-la-comision-europea.

SPANDA Foundation (2014). On The move. Unaccompanied Foreign Minors in the European Union. Den Haag, Países Bajos: SPANDA Foundation. Recuperado de http://www.spanda.org/On_the_MoveL.pdf. 
SUÁREZ, L. (2006). Un nuevo actor migratorio: Jóvenes, rutas y ritos transnacionales. En A. Árjona Garrido, F. Checa y Olmos y J. C. Checa Olmos (eds.). Menores tras la frontera. Otra inmigración que aguarda (pp. 17-50). Barcelona, España: Icaria.

\section{Documentos oficiales de la Unión Europea}

Comisión Europea (2012). Informe de la Comisión al Consejo y al Parlamento Europeo. Informe intermedio de la aplicación del Plan de acción sobre los menores no acompañados. COM (2012) 554 final. Bruselas, 28.9.2012. Recuperado de http://www.acnur.org/fileadmin/scripts/doc.php?file=fileadmin/Documentos/ $\mathrm{BDL} / 2013 / 9247$.

Comisión Europea (2014). Un Sistema Europeo Común de Asilo. Bruselas, Bélgica: Oficina de la Unión Europea. DOI: 10.2837/66073.

Comisión Europea (2010). Comunicación de la Comisión al Parlamento Europea y al Consejo. Plan de acción sobre los menores no acompañados (2010-2014). COM (2010) 213 final. Recuperado de http://eur-lex.europa.eu/legalcontent/.

Consejo de la Unión Europea (2008). Directiva 2008/115/EC de 16 de diciembre de 2008 relativa a normas y procedimientos comunes en los Estados miembros para el retorno de los nacionales de terceros países en situación irregular. DO L. 348/98-348/107. 16.12.2008. 2008/115/EC.

Comisión Europea (2011). Comunicación de la Comisión al Parlamento Europeo al Consejo, al Comité Económico y Social Europeo y al Comité de las Regiones de 15 de febrero de 2011 denominada Una Agenda de la UE en pro de los Derechos del Niño. COM/2011/60/final. Recuperado de http://eur-lex.europa.eu/legalcontent/ES/TXT/?uri=celex:52011DC0060.

Directiva 2001/55/CE del Consejo de 20 de julio de 2001 relativa a las normas mínimas para la concesión de protección temporal en caso de afluencia masiva de personas desplazadas y a medidas de fomento de un esfuerzo equitativo entre los Estados miembros para acoger a dichas personas y asumir las consecuencias de su acogida. Directiva 2003/9/CE del Consejo de 27 de enero de 2003 por la que se aprueban normas mínimas para la acogida de los solicitantes de asilo en los Estados miembros.

Directiva 2003/86/CE del Consejo de 22 de septiembre de 2003 sobre el derecho a la reagrupación familiar.

Directiva 2004/81/CE del Consejo de 29 de abril de 2004, relativa a la expedición de un permiso de residencia a nacionales de terceros países que sean víctimas de la trata 
de seres humanos o hayan sido objeto de una acción de ayuda a la inmigración ilegal, que cooperen con las autoridades competentes.

Directiva 2004/83/CE del Consejo de 29 de abril de 2004 por la que se establecen normas mínimas relativas a los requisitos para el reconocimiento y el estatuto de nacionales de terceros países o apátridas como refugiados o personas que necesitan otro tipo de protección internacional y al contenido de la protección concedida.

Directiva 2005/85/CE del Consejo de 1 de diciembre de 2005 sobre normas mínimas para los procedimientos que deben aplicar los Estados miembros para conceder o retirar la condición de refugiado. Diario Oficial de la Unión Europea L 326/13. 13.12.2005 Recuperado de http://eur-lex.europa.eu/legal-content/ES/TXT/PD $\mathrm{F} /$ ?uri=CELEX:32005L0085\&from=ES.

Directiva 2011/95/UE del Parlamento Europeo y del Consejo de 13 de diciembre de 2011 por la que se establecen normas relativas a los requisitos para el reconocimiento de nacionales de terceros países o apátridas como beneficiarios de protección internacional a un estatuto uniforme para los refugiados o para las personas con derecho a protección subsidiaria y al contenido de la protección concedida. Diario Oficial de la Unión Europea L 337/9 20.12.2011. Recuperado de https:// web.icam.es/bucket/DIRECTIVA\%2095\%202011\%20CALIFICACION\%20 L00009-00026.pdf.

Reglamento (UE) no. 604/2013 del Parlamento Europeo y del Consejo de la Unión Europea, de 26 de junio de 2013 por el que se establecen los criterios y mecanismos de determinación del Estado miembro responsable del examen de una solicitud de protección internacional presentada en uno de los Estados miembros por un nacional de un tercer país o apátrida. Recuperado de https://www.boe.es/diario_boe/ txt.php?id=DOUE-L-2013-81288.

Unión Europea (2000). Carta de los Derechos Fundamentales de la Unión Europea (2000/C 364/01). Diario Oficial de las Comunidades Europeas. 18.12.2000. Recuperado de http://www.europarl.europa.eu/charter/pdf/text_es.pdf.

Unión Europea. Versiones consolidadas del Tratado de la Unión Europea y del Tratado de Funcionamiento de la Unión Europea. Versión consolidada del Tratado de la Unión Europea. Versión consolidada del Tratado de Funcionamiento de la Unión Europea. Protocolos-Anexos-Declaraciones anejas al Acta Final de la Conferencia intergubernamental que ha adoptado el Tratado de Lisboa firmado el 13 de diciembre de 2007. Tablas de correspondencias. Diario Oficial de la UE C 326. 26.10.2012 Recuperado de http://eur-lex.europa.eu/legal-content/ES/ TXT/PDF/?uri=CELEX:12012M/TXT\&from=ES. 
Unión Europea (1997). Resolución del Consejo relativa a los menores no acompañados nacionales de países terceros países (97/C 221/03) de 26 de junio de 1997. Diario Oficial de las Comunidades Europeas C 221/23 19.7.1997. Recuperado de http:// eur-lex.europa.eu/legal-content/ES/TXT/PDF/?uri=CELEX:31997Y0719(02) $\&$ from $=\mathrm{ES}$.

\section{Documentos oficiales de Naciones Unidas y otros organismos internacionales}

Consejo de Europa (1950). Convenio Europeo de Derechos Humanos. Recuperado de http://www.echr.coe.int/Documents/Convention_SPA.pdf.

EUROSTAT (2015). Asylum applicants considered to be unaccompanied minors - annual data. Recuperado de http://ec.europa.eu/eurostat/tgm/table.do?tab=table\&init $=1 \&$ language $=$ en $\&$ pcode $=$ tps $00194 \&$ plugin $=1$.

EUROSTAT (2015), Asylum quarterly report. Statistics Explained. Recuperado de http://ec.europa.eu/eurostat/statistics-explained/index.php/Asylum_quarterly_report\#cite_ref-3( recuperada en 27 del 12 del 2015).

EUROSTAT (14 de julio de 2016). Asylum quarterly report. Statistics Explained. First Quarter of 2016. Recuperado de http://ec.europa.eu/eurostat/statistics-explained/ index.php/Asylum_quarterly_report.

Naciones Unidas (1989). Convención sobre los Derechos del Niño de 20 noviembre de 1989. Recuperado de http://www.ohchr.org/SP/ProfessionalInterest/Pages/ CRC.aspx.

Naciones Unidas (2005). Observación General No. 6. Trato de los menores no acompañados y separados de su familia fuera de su país de origen. Comité de los Derechos del Niño. CRC/GC/2005/6. Recuperado de http://www.unicef.cl/web/informes/ derechos_nino/06.pdf

Organización Internacional para las Migraciones (2016). El balance actualizado hasta el 15 de febrero de 2016 confirma una cifra de 10011712 . Recuperado de http://www. iom.int/news/mediterranean-migrant-and-refugee-arrivals-top-83000-2016.

UNHCR (United Nations High Commissioner for Refugees) (2006). Guidelines on Determining the Best Interests of the Child. Recuperado de http://www.unhcr. org/4566b16b2.pdf. 